\title{
DIAGNOSTIC UTILITY OF SERUM LACTATE DEHYDROGENASE LEVELS (LDL) IN DIFFERENTIATING MEGALOBLASTIC ANEMIA FROM MYELODYSPLASTIC SYNDROMES IN PAKISTAN
}

\author{
Faraz Ali Rana, Helen Mary Robert, Madiha Ilyas*, Asad Mahmood, Muhammad Amir, Nabeela Khan \\ Armed Forces Institute of Pathology/National University of Medical Sciences (NUMS) Rawalpindi Pakistan, *Government College Women University, \\ Faisalabad Pakistan
}

\begin{abstract}
Objective: To study the diagnostic utility of lactate dehydrogenase levels in differentiating megaloblastic anemia from myelodysplastic anemia in Pakistan.

Study Design: Comparative cross-sectional study.

Place and Duration of Study: Department of Hematology, Armed Forces Institute of Pathology, Rawalpindi Pakistan, from Feb to Aug 2019.

Methodology: In this study, total 240 patients (18-75 years of age) males and females were selected by consecutive sampling technique and were equally divided into 3 groups; patients with megaloblastic anemia, patients with myelodysplastic syndromes and healthy control group. The clinical history and duration of anemia were recorded on special designed proforma. The laboratory investigations including lactate dehydrogenase levels were also noted. Both types of anemia were compared on basis of Lactate Dehydrogenase Levels.

Results: The lactate dehydrogenase levels in megaloblastic group were more than $3000 \mathrm{IU} / \mathrm{L}$ in 58 out of 80 patients $(72.5 \%)$. On other hand, myelodysplastic group had 79 out of 80 patients with lactic acid dehydrogenase levels below $450 \mathrm{IU} / \mathrm{L}$ (98.75\%). The difference in lactic acid dehydrogenase levels between both groups was found to be statistically significant. Conclusion: Serum lactate dehydrogenase levels can be used to differentiate megaloblastic anemia from other anemia especially myelodysplastic syndromes before doing a bone marrow examination. High lactate dehydrogenase levels above 3000 $\mathrm{IU} / \mathrm{L}$ in megaloblastic anemia can differentiate it from other anemia.
\end{abstract}

Keywords: Anemia, Megaloblastic anemia, Myelodysplastic anemia, Serum lactate dehydrogenase levels.

How to Cite This Article: Rana FA Robert HM, Ilyas M, Mahmood A, Amir M, Khan N. Diagnostic Utility of Serum Lactate Dehydrogenase Levels (LDL) in Differentiating Megaloblastic Anemia from Myelodysplastic Syndromes in Pakistan. Pak Armed Forces Med J 2021; 71(5): 1539-1543. doi: https://doi.org/10.51253/pafmj.v71i5.5003

This is an Open Access article distributed under the terms of the Creative Commons Attribution License (https://creativecommons.org/licenses/by-nc/4.0/), which permits unrestricted use, distribution, and reproduction in any medium, provided the original work is properly cited.

\section{INTRODUCTION}

Anaemia is a major health concern that affects the every age group and gender worldwide. According to World Health Organization (WHO), the global prevalence of anaemia is $24.8 \%$, which means about 1.62 billion people worldwide are affected by anemia every year. One of the most common types of anemia is megaloblastic anemia and its incidence has increased over the last 2 decades worldwide. ${ }^{1}$ It poses a considerable health problem in developing countries like India and Pakistan and its highest incidence has been reported from India and Africa ranging from $50-71 \%$ which is seen more in the younger age group. ${ }^{2}$ The main causes of megaloblastic anemia includes vitamin B12 deficiency and folic acid deficiency. In megaloblastic anemia, macrocytes, macro-ovalocytes and hypersegmented neutrophils are seen on peripheral blood smear which

Correspondence: Dr Faraz Ali Rana, Department of Haematology, Armed Forces Institute of Pathology, Rawalpindi Pakistan

Received: 13 Aug 2020; revision received: 01 Jan 2021; accepted: 11 Jan 2021 provide supportive evidence. ${ }^{3}$

However, for the definitive confirmatory diagnosis of megaloblastic anemia, bone marrow examination is required which is an invasive procedure and may not be available at peripheral centers. ${ }^{4}$ For the diagnosis of megaloblastic anemia various investigations are used that include blood count, peripheral smear examination, serum vitamin B12 assay, red cell folate assay, serum folate assay and other useful investigations like serum/plasma methylmalonic acid (MMA), plasma total homocysteine (tHCYS) and serum holo-transcobalamin II assay. Many of these specialized investigations are expensive and required special equipments, materials and expertise which may not be available everywhere. ${ }^{4}$ Lactate dehydrogenase is a true intracellular enzyme which was first seen to be grossly elevated in megaloblastic anemia cases. ${ }^{5}$ Since then a number of studies have documented the role of serum lactate dehydrogenase in diagnosing megaloblastic anemia. Therefore, serum lactate dehydrogenase estimation can be used as a screening test for the diagnosis of 
megaloblastic anemia before performing a bone marrow aspiration. ${ }^{2}$

The myelodysplastic syndromes are a group of bone marrow diseases that have susceptibility to evolve into acute leukemia and are common in patients who have undergone therapy for malignancy. ${ }^{5}$ The peripheral smear changes in myelodysplastic syndromes include pseudo-Pelger Huet cells (two lobed neutrophils), macro ovalocytes and hypo-segmented neutrophils. This is commonly seen in older patients and manifests itself as an anemia with normal iron, vitamin B12, and folate studies. ${ }^{6}$ Often these patients are misdiagnosed and treated with iron or vitamin supplements. The diagnosis of this condition is by bone marrow examination and genetics studies which are extremely expensive. Important laboratory values that support or exclude the diagnosis of Myelodysplastic syndromes are lactate dehydrogenase (LDH), ferritin, transferrin and transferrin saturation, reticulocyte counts, vitamin B12 and folate concentrations, haptoglobin, endogenous erythropoietin (EPO) and creatinine levels. They can serve to exclude the differential diagnoses of iron deficiency anaemia, haemolytic anaemia, vitamin B12 or folate deficiency and renal anaemia. ${ }^{7}$ A number of studies have shown that an elevated serum lactate dehydrogenase (LDH) is associated with a poor prognosis in Myelodysplastic syndromes and is a usual predictor of prognosis in such patients. ${ }^{8}$ Therefore, the study is planned to utilize serum lactate dehydrogenase levels for differential diagnosis of megaloblastic anemia from myelodysplastic syndromes.

The aim of the study was to utilize lactate dehydrogenase levels which are an important diagnostic tool in differentiating megaloblastic anemia from other anemia such as myelodysplastic syndromes. As Pakistan is a poor country and bone marrow examination is an invasive and expensive modality, a simple test is necessary to help in early diagnosis of patients with anemia. Thus, we underwent a study to compare the lactate dehydrogenase levels in patients with megaloblastic anemia and myelodysplastic syndromes in Pakistani population.

\section{METHODOLOGY}

A comparative cross-sectional study was conducted at the department of Hematology, Armed Forces Institute of Pathology. After the ethical approval from IRB institutional committee certificate number FCHEM18-10/READ-IRB/20/363 and patient's informed consent, 240 patients were selected by consecutive sampling technique and 80 patients were assorted in each group i.e. i) Patients with megaloblastic anemia, ii) Patients with myelodysplastic syndrome along with Control group (in which healthy patients were taken with normal hemoglobin).

Inclusion Criteria: The patients of megalo-blastic and myelodysplastic syndrome (aged between 10-75 years of age) both males and females.

Exlcusion criteria: The patients with hemolytic anemia, iron deficiency anemia, aplastic anemia, leukemia, pregnant and lactating women, alcoholic, having liver disease and hypothyroidism.

The demographic details of patients of both groups were collected, height and weight were measured and detailed clinical history was obtained. History of co-morbid conditions was also documented. Duration of anemia and signs and symptoms were recorded. In blood analysis, CBC, peripheral smear, hematological parameters and total serum LDH levels were estimated. The Investigations like reticulocyte count, sickling test, $\mathrm{Hb}$ electrophoresis, serum iron, serum total iron binding capacity (TIBC) and bone marrow aspiration were also done wherever required for diagnosis. ${ }^{7}$ The normal values of LDH were taken as 140$280 \mathrm{IU} / \mathrm{L} 9$.

Data was analyzed by using Statistical Package for Social Sciences (SPSS) version 21. Means were estimated and presented as mean $\pm \mathrm{SE}$. To compare the means of the LDH values in 2 groups of anemia and control, t-test was used.

\section{RESULTS}

This study comprised of 80 healthy patients, 80 patients in megaloblastic anemia group and 80 patients in myeloblastic anemia group. The results of the present study showed the mean lactate dehydrogenase levels in all the groups. The control group had normal serum LDH levels of mean range of $199.86 \pm 45.21$. The megaloblastic group had high LDH levels having mean value i.e. $3623.30 \pm 821.75$. Whereas the myelodysplastic group had LDH levels of mean value i.e. 339.30 \pm 49.73 (Table-I).

The maximum patients in megaloblastic group were found within the age group of 10 to 20 years $(68.75 \%)$. On the other hand, the maximum patients in myelodysplastic group were found to be more than 70 years $(81.25 \%)$ (Table-II).

Female predominance of $60 \%$ was seen in megaloblastic anemia group, whereas male preponderance of $65 \%$ was seen in myelodysplastic group. The control 
Table-I: Serum lactate dehydrogenase levels level in study groups.

\begin{tabular}{|c|c|c|c|c|c|}
\hline \multicolumn{2}{|l|}{ Group } & $\begin{array}{l}\text { No. of } \\
\text { Study }\end{array}$ & Range & & Mean \pm SD \\
\hline \multicolumn{2}{|l|}{ Control } & 80 & $128-289$ & \multicolumn{2}{|c|}{$199.86 \pm 45.21 \mathrm{IU} / \mathrm{L}$} \\
\hline \multicolumn{2}{|l|}{ Megaloblastic } & 80 & $2097-5890$ & \multicolumn{2}{|c|}{$3623.3 \pm 821.75 \mathrm{IU} / \mathrm{L}$} \\
\hline \multicolumn{2}{|c|}{ Myelodysplastic } & 80 & $251-455$ & \multicolumn{2}{|c|}{$339.3 \pm 49.73 \mathrm{IU} / \mathrm{L}$} \\
\hline \multicolumn{6}{|c|}{ Table-II: Age-wise distribution of study groups. } \\
\hline \multirow{2}{*}{$\begin{array}{l}\text { Age Group } \\
\text { (years) }\end{array}$} & \multicolumn{5}{|c|}{ Groups } \\
\hline & & Control & \multicolumn{2}{|c|}{ Megaloblastic } & Myelodysplastic \\
\hline$\leq 10$ & \multicolumn{2}{|c|}{ Not detected } & \multicolumn{2}{|c|}{$20(25 \%)$} & Not detected \\
\hline $10-20$ & \multicolumn{2}{|c|}{$13(16.25 \%)$} & \multicolumn{2}{|c|}{$55(68.75 \%)$} & Not detected \\
\hline $20-30$ & \multicolumn{2}{|c|}{$25(31.25 \%)$} & \multicolumn{2}{|c|}{$5(6.25 \%)$} & Not detected \\
\hline $30-40$ & \multicolumn{2}{|c|}{$21(26.25 \%)$} & \multicolumn{2}{|c|}{ Not detected } & Not detected \\
\hline $40-50$ & \multicolumn{2}{|c|}{$9(11.25 \%)$} & \multicolumn{2}{|c|}{ Not detected } & Not detected \\
\hline $50-60$ & \multicolumn{2}{|r|}{$4(5 \%)$} & \multicolumn{2}{|c|}{ Not detected } & $1(1.25 \%)$ \\
\hline $60-70$ & \multicolumn{2}{|c|}{$7(8.75 \%)$} & \multicolumn{2}{|c|}{ Not detected } & $14(17.50 \%)$ \\
\hline$>70$ & \multicolumn{2}{|c|}{$1(1.25 \%)$} & \multicolumn{2}{|c|}{ Not detected } & $65(81.25 \%)$ \\
\hline
\end{tabular}

group had an almost equal distribution of males and females (Table-III).

The hemoglobin levels in both megaloblastic anemia group and myelodysplastic group had minor difference showing a mean hemoglobin levels of $8.91 \mathrm{~g} / \mathrm{L}$ in megaloblastic group and $9.43 \mathrm{~g} / \mathrm{L}$ in myelodysplastic group respectively as compared to control $(13.51 \mathrm{~g} / \mathrm{L})$ (Table-IV).
Table-V: Distribution of study groups within different ranges of total serum lactate dehydrogenase level.

\begin{tabular}{l|c|c|c|c}
\hline Groups & $\begin{array}{c}\leq 450 \\
\text { IU/L }\end{array}$ & $\begin{array}{c}451-900 \\
\text { IU/L }\end{array}$ & $\begin{array}{c}\mathbf{9 0 1 - 3 0 0 0} \\
\text { IU/L }\end{array}$ & $\begin{array}{c}>3001 \\
\text { IU/L }\end{array}$ \\
\hline Control & 80 & - & - & - \\
\hline Megaloblastic & - & - & $22(27.5 \%)$ & $58(72.5 \%)$ \\
\hline $\begin{array}{l}\text { Myelodys- } \\
\text { plastic }\end{array}$ & $\begin{array}{c}79 \\
(98.75 \%)\end{array}$ & $1(1.25 \%)$ & - & - \\
\hline
\end{tabular}

everywhere. ${ }^{7}$ There is a dire need to find out markers that can help in early diagnosis and treatment. Lactate dehydrogenase levels were used in this study to help in the diagnosis and differentiate between megaloblastic anemias and myelodysplastic syndromes. In megaloblastic anemia high Lactate dehydrogenase levels were observed due to high Lactate dehydrogenase content in megaloblasts and intramedullary destruction of megaloblasts. ${ }^{4}$

In this study majority of patients of megaloblastic anemia had Lactate dehydrogenase levels above 3000 $\mathrm{IU} / \mathrm{l}$, whereas maximum number of patients of myelodysplastic syndromes Lactate dehydrogenase levels were $<450 \mathrm{IU} / 1$. This finding was similar to a study, that showed that maximum number of megaloblastic cases [33 (80.49\%)] had Lactate dehydrogenase values

Table-III: Gender-wise distribution of study groups.

\begin{tabular}{|c|c|c|c|c|c|}
\hline Group & $\mathbf{n}$ & Male (\%) & Female (\%) & Mean \pm SD & $p$-value \\
\hline Control spread & 80 & $42(52.5 \%)$ & $38(47.5 \%)$ & $34.94 \pm 14.72$ & $<0.01$ \\
\hline Megaloblastic spread & 80 & $32(40 \%)$ & $48(60 \%)$ & $13.48 \pm 4.29$ & \\
\hline Control spread & 80 & $42(52.5 \%)$ & $38(47.5 \%)$ & $34.94 \pm 14.72$ & $<0.01$ \\
\hline Myelodysplastic spread & 80 & $52(65 \%)$ & $28(35 \%)$ & $75.49 \pm 5.99$ & \\
\hline Megaloblastic spread & 80 & $32(40 \%)$ & $48(60 \%)$ & $13.48 \pm 4.29$ & $<0.01$ \\
\hline Myelodysplastic spread & 80 & $52(65 \%)$ & $28(35 \%)$ & $75.49 \pm 5.99$ & \\
\hline \multicolumn{6}{|c|}{ Table-IV: Comparison among the groups regarding hemoglobin level. } \\
\hline Group & $\mathbf{n}$ & Mean \pm SD & Standard Error & T-value & $p$-value \\
\hline Control & 80 & $13.51 \pm 1.23 \mathrm{~g} / \mathrm{L}$ & 0.138 & $28.24^{* *}$ & $<0.01$ \\
\hline Megaloblastic & 80 & $8.91 \pm 0.77 \mathrm{~g} / \mathrm{L}$ & 0.086 & & \\
\hline Control & 80 & $13.51 \pm 1.23 \mathrm{~g} / \mathrm{L}$ & 0.138 & $25.64^{* *}$ & $<0.01$ \\
\hline Myelodysplastic & 80 & $9.43 \pm 0.71 \mathrm{~g} / \mathrm{L}$ & 0.079 & & \\
\hline Megaloblastic & 80 & $8.91 \pm 0.77 \mathrm{~g} / \mathrm{L}$ & 0.086 & $-4.45^{* *}$ & $<0.01$ \\
\hline Myelodysplastic & 80 & $9.43 \pm 0.71 \mathrm{~g} / \mathrm{L}$ & 0.079 & & \\
\hline
\end{tabular}

The LDH levels in megaloblastic group were more than $3000 \mathrm{IU} / \mathrm{L}$ in 58 out of 80 patients and on other hand, myelodysplastic group had 79 out of 80 patients with LDH levels below $450 \mathrm{IU} / \mathrm{L}$ (Table-V).

\section{DISCUSSION}

Megaloblastic anemia and myelodysplastic syndromes are common health conditions in Pakistan which requires bone marrow aspiration for diagnosis. Bone marrow aspiration is an invasive expensive diagnostic procedure for these anemia which is not available of more than $3000 \mathrm{IU} / \mathrm{L} 2$.

In this study, the mean Lactate dehydrogenase levels in megaloblastic anemia group were approximately 18 times that of control group. These results were in accordance with a study by Kannan et al, which reported the serum Lactate dehydrogenase levels in megaloblastic anemia patients were around 54 times greater than the normal value. ${ }^{11}$

A study by Stein et al, also found that the serum Lactate dehydrogenase levels in megaloblastic anemia 
cases were significantly raised to 1.3 to 24 times as compared to control. ${ }^{12}$

In this study, the megaloblastic group patients showed female predominance and were mostly in age group between 10-20 years. These results were in contrast with findings of a study by Pandya et al, which showed that males were more affected from megaloblastic anemia than the females and showed peak incidence in age groups of $40-49$ years which is a much older age group than our study findings. ${ }^{13}$ A similar study to our study results were a study by Amrapal et $a l$, which found a peak age incidence in megaloblastic patients between age groups of 11-40 years 2 . The difference of gender between our study and these studies might be due to cultural differences. An Indian study by Khanduri et al showed similar results of our study with a peak incidence of megaloblastic anaemia in the age group of $10-30$ years (48\%), with a female preponderance $(71 \%)$. However, our study showed that myelodysplastic syndromes were more common in males and were majority above 70 years old. The existing data from various studies also revealed that myelodysplastic syndromes are predominately a disease of the elderly. ${ }^{14}$ A case report also revealed a 66 year old African female with myelodysplastic syndome who was suffering from anemia and they remained undiagnosed. Therefore, elderly patients need assessment regarding myelodysplastic syndromes. In this case report it was also found that her Lactate dehydrogenase levels were high at $1248 \mathrm{IU} / \mathrm{L}$.

However, in our present study the myelodysplastic patients had slightly elevated Lactate dehydrogenase levels of mean around $339 \mathrm{IU} / \mathrm{L}$. These findings were in accordance with the study, which showed a median Lactate dehydrogenase levels of $206 \mathrm{IU} / 1$ at time of diagnosis which rose to approximately $70 \mathrm{IU} / 1$ over a 3-month period. ${ }^{15}$

Thus, from findings of our study it can be seen that serum Lactate dehydrogenase levels can be used as a simple, less invasive test in the diagnosis of megaloblastic anemia, when the values are more than 3000 IU/L. Whereas, values of Lactate dehydrogenase levels less than $3000 \mathrm{IU} / \mathrm{L}$ were observed in other anemia such as myelodysplastic syndromes. Lactate dehydrogenase levels proved to be a useful test in the early diagnosis of megaloblastic anemias. ${ }^{16}$

Several parameters for the diagnosis of megaloblastic anemia were used which include B12 and folate assays, serum methylmalonic acid (MMA), plasma total homocysteine (tHCYS) and serum holo-transcoba- lamin II assays. ${ }^{17}$ However, all these tests are not widely available and have limitations in their sensitivity and specificity. ${ }^{18}$

\section{ACKNOWLEDGMENT}

We would like to acknowledge all the technical and supporting staff in AFIP for their cooperation during the research work.

\section{CONCLUSION}

Serum Lactate Dehydrogenase levels (LDH) can be used to diagnose megaloblastic anemia from other anemia especially myelodysplastic syndromes before performing a Bone marrow examination. This could be inexpensive in comparison to bone marrow aspiration analysis and can lead to early diagnosis of patients with megaloblastic anemia.

\section{Conflict of Interest: None.}

\section{Authors' Contribution}

FAR: Substantial contributions to conception and design, acquisation of data, analysis and interpretation of data, HMR: Technical guidance, review and final approva of final version, MI: Drafting of article, revising it critically for important intellectual content, AM: General support, MA: General support.

\section{REFERENCES}

1. Agarwal L, Ramawat J, Agrawala M, Rai N. A study on prevalence and causative factors of megaloblastic anaemia in hadoti region. Annals Appl Bio Sci 2017; 4(1): 2349-2391.

2. Amrapal L, Gaikwad, Jadhav DS. Utility of serum lactate dehy-drogenase in the diagnosis of megaloblastic anemia. Int J Res Med Sci 2018; 6(9): 3051-3056.

3. Jaswal TS, Mehta HC, Gupta V, Singh M, Singh S. Serum lactate dehydrogenase in diagnosis of megaloblastic anaemia. Ind J Pathol Microbiol 2000; 43(3): 325-329.

4. Chaudhari S, Bindu S. Correlation of Lactate Dehydrogenase in Megaloblastic Anemia. Int J Curr Med and Appl Sci 2015; 9(1): 28-32.

5. Xiaomei Ma. Epidemiology of myelodysplastic syndromes. Am J Med 2012; 125(7): S2-S5.

6. Bastida JM, López-Godino O, Vicente-Sánchez A, BonanadBoix S, Xicoy-Cirici B, Hernández-Sánchez JM, et al. Hidden myelody-splastic syndrome (MDS): A prospective study to confirm or exclude MDS in patients with anemia of uncertain etiology. Int J Lab Hematol 2019; 41(1): 109-117.

7. Cakmakli HF, Torres RJ, Menendez A, Yalcin-Cakmakli G, Porter CC, Puig JG, et al. Macrocytic anemia in Lesch-Nyhan disease and its variants. Genet Med 2019; 21(2): 353-360.

8. Martínez SFM, Jácome ECP, Guevara, E. Case report myelodysplastic syndrome clinically presenting with the (Classic TTP Pentad). Case Rep Hematol 2017; 2017(2): 4619406.

9. Vašeková P, Szépe P, Marcinek J, Balhárek T, Plank L. Clinically relevant possibilities and limits of differential diagnosis of mega-loblastic anemia and myelodysplastic syndromerefractory anemia type in bone marrow biopsies. Vnitr Lek 2016; 62(9): 692-697.

10. Steel RGD, Torrie JH, Dickey DA. $3^{\text {rd }}$ Ed. Principles and proce-dures of statistics: A biometrical approach 1997, McGraw Hill Book Co, New York, USA, [Internet] Available 
from:https://books.google.com.pk/books/about/ Principles_and_Procedures_of_Statistics.html?id $=$ XBbvAAAAMAAJ\&redir_esc $=y$

11. Kannan A, Tilak V, Rai M, Gupta V. Evaluation of clinical, bio-chemical and hematological parameters in macrocytic anemia. Int J Res Med Sci 2016; 4(7): 2670-2678.

12. Stein ID. Elevated serum lactate dehydrogenase activity in megaloblastic anemia-some current explanations re-examined. Am J Clin Pathol 1973; 59(1): 122-123.

13. Pandya HP, Patel A. Clinical profile and response in patients with megaloblastic anemia. Int J Med Sci Public Health 2016; 5(2): 304-306.

14. Khanduri U, Sharma A. Megaloblastic anaemia: prevalence and causative factors. Natl Med J Ind 2007; 20(4): 172-175.
15. Wimazal F, Sperr WR, Kundi M, Vales A, Fonatsch C, Thalham-mer-Scherrer $R$, et al. Prognostic significance of serial determinations of lactate dehydrogenase in the followup of patients with myelodysplastic syndromes. Ann Oncol 2008; 19(5): 970-976.

16. Bates I. Reference ranges and normal values.In: Bain BJ, Bates I, Laffan MA, Lewis SM. 12 $2^{\text {th }}$ ed. Dacie and Lewis Practical Haematology. Elsevier, China 2017, [Internet] Available from: https://www.elsevier.com/books/dacie-and-lewispractical-haematology/bain/978-0-7020-6696-2

17. Gore BP, Kurundkar G. Retrospective study of serum LDH in megaloblastic anemia. Ind J App Res 2015; 5(1): 454-455.

18. Wickramasinghe SN. Diagnosis of megaloblastic anemias. Blood Rev 2006; 20(6): 299-318. 